\title{
Use of an electronic metabolic monitoring form in a mental health service - a retrospective file audit
}

\author{
Brenda Happell ${ }^{1}$, Chris Platania-Phung ${ }^{1}$, Cadeyrn J. Gaskin ${ }^{2,3}$ and Robert Stanton ${ }^{2}$
}

\begin{abstract}
Background: People with severe mental illness have poorer physical health, experience disparities in physical health care, and lead significantly shorter lives, compared to the general population. Routine metabolic monitoring is proposed as a method of identifying risk factors for metabolic abnormalities. Efforts to date suggest routine metabolic monitoring is both incomplete and ad-hoc, however. This present study reports on the recent implementation of a routine metabolic monitoring form at a mental health service in regional Australia.

Methods: A retrospective file audit was undertaken on 721 consumers with electronic health records at the mental health service. Descriptive statistics were used to report the frequency of use of the metabolic monitoring form and the range of metabolic parameters that had been recorded.

Results: Consumers had an average age of 41.4 years $(S D=14.6)$, over half were male $(58.4 \%)$, and the most common psychiatric diagnosis was schizophrenia (42.3\%). The metabolic monitoring forms of $36 \%$ of consumers contained data. Measurements were most commonly recorded for weight ( $87.4 \%$ of forms), height ( $85.4 \%$ ), blood pressure (83.5 \%), and body mass index (73.6\%). Data were less frequently recorded for lipids (cholesterol, $56.3 \%$; low density lipoprotein, $48.7 \%$; high density lipoprotein, $51.7 \%$; triglycerides, $55.2 \%$ ), liver function (alanine aminotransferase, $66.3 \%$; aspartate aminotransferase, $65.5 \%$; gamma-glutamyl transpeptidase, $64.8 \%$ ), renal function (urea, $66.3 \%$; creatinine, $65.9 \%$ ), fasting blood glucose (60.2\%), and waist circumference (54.4\%).

Conclusions: The metabolic monitoring forms in consumer electronic health records are not utilised in a manner that maximises their potential. The extent of the missing data suggests that the metabolic health of most consumers may not have been adequately monitored. Addressing the possible reasons for the low completion rate has the potential to improve the provision of physical health care for people with mental illness.
\end{abstract}

Keywords: Cardiometabolic, Mental health service, Monitoring, Physical health, Severe mental illness

\section{Background}

People with severe mental illnesses (SMI) -such as schizophrenia, bipolar disorder, and major depressive disorder - have substantially poorer physical health than the general population $[1,2]$. They are at increased risk of many physical health problems, including cardiovascular diseases, obesity, metabolic syndrome, and dyslipidaemia [1]. As a result, people with SMI have a reduced life expectancy of between 1.4 and 32 years

\footnotetext{
* Correspondence: r.stanton@cqu.edu.au

${ }^{2}$ School of Medical and Applied Sciences, Central Queensland University,

Bruce Highway, North Rockhampton, QLD 4702, Australia

Full list of author information is available at the end of the article
}

(median $=10.1$ years) $[3]$. Several lifestyle behaviours (e.g., unhealthy diets, physical inactivity, smoking, alcohol and drug use, and unsafe sex) are known to be contribute to this reduction in life expectancy [4]. In addition, anti-psychotic medication and other psychotropic drugs are known to be major contributors to the ill-health of people with SMI [5-9]. Many factors contributing to the increased risk of cardiovascular and all-cause mortality in people with SMI are modifiable, however [10]. Health care providers, including mental health services, have an important role in identifying and monitoring these risks [11]. 
The provision of inadequate health care for people with SMI is a major form of inequality $[12,13]$. Monitoring of risk factors for poor cardiometabolic health (known as metabolic monitoring) would represent a significant step towards equity in health care provision [14]. As in the general populations, metabolic monitoring in people with SMI is necessary to quantify the risk of cardiovascular disease and diabetes, and initiate early interventions for risk management [15].

Internationally, the level of comprehensive metabolic care offered to people with mental illness is consistently found to be inadequate [16]. Research included in this review comparing the quality of care of people with and without mental illness, showed that people with mental illness taking anti-psychotic medications were $30 \%$ less likely to have their weight, blood glucose, and lipids assessed [16]. Using chart reviews, clinical and administrative data, Littman et al. [17] estimated rates of screening for obesity (defined by body mass index) to be between $94-94.7 \%$ in a sample of 37,889 veterans from the Veterans Health Administration in the USA. However, when multiple metabolic risks are considered, monitoring performance is quite variable. Consistent with this evidence, the authors of a recent review reported substantial variability in the rates cardiovascular health screening in people with SMI, which the authors suggested were due to differences in the organization of health care [18]. In a recent study, Cotes et al. [19] inspected medical records within a public-funded community health service in a US state, to ascertain if an education program on the metabolic monitoring of consumers taking antipsychotics would improve monitoring levels. They found a statistically non-significant increase in the frequency of metabolic monitoring, even though the program included feedback on performance at monitoring metabolic risks. Similarly, Saloojee et al. [20] identified that less than one per cent of outpatients at a large South African hospital were screened on the set of risk factors needed to identify metabolic syndrome. Poor monitoring was occurring despite the availability of guideline recommendations on metabolic care of people with SMI in South Africa. Collectively, these studies confirm the variability of metabolic monitoring practices in several countries.

In considering the poor rate of implementation of metabolic care activities, many health care systemrelated factors (e.g., lack of role clarity within treating teams regarding responsibility for screening, lack of continuity of care, limited time and resources for physical and medical examinations, separation of medical and mental health care systems) represent significant barriers to change [21, 22]. Moreover, nurses working in mental health have reported personal barriers to monitoring, such as competing priorities and concerns regarding the outcomes of screening [23]. The increased metabolic risks for people with SMI are well documented [24], particularly for those consumers prescribed anti-psychotic medication $[1,9]$. Therefore, it is fundamental to clinical practice to have routine and detailed metabolic monitoring to track changes in risk to inform clinical decisionmaking.

There is limited data on metabolic monitoring rates in Australian mental health care services, with reports primarily available from metropolitan, rather than regional and rural, areas [25] e.g. [26]. Organ et al. [27] reported that around $60 \%$ of consumers files contained data on lipid and blood glucose levels, whereas only $7 \%$ of consumers with SMI had their weight circumference recorded. The absence of waist circumference measurement is also reported in other studies. For example, Rosenbaum and colleagues [28] reported that, prior to an educational intervention for nurses highlighting the importance of waist circumference assessment, these data were not reported in any of the 60 randomly sampled consumer files selected for auditing. Three months later, $58 \%$ of files contained waist circumference measurements, while at nine months this reduced to $42 \%$. Although barriers to waist circumference measurement (such as concern regarding physical contact) exist, the study of Rosenbaum and colleagues [28] demonstrated that educational interventions for nurses can improve the assessment of cardiometabolic markers in people with SMI.

Thompson et al. [29] reported metabolic monitoring levels of consumers with first episode psychosis on a regimen of anti-psychotic medications in a service adopting locally adapted monitoring guidelines. Blood pressure data was reported in $41.6 \%$ of files reviewed, blood glucose data was reported in $24.4 \%$ of cases, while lipids were reported in $26.7 \%$ of files. In the same 86 consumers tracked over six months, initial recordings (screening stage) were higher - 81.4\%, 74.4 \% and $75.6 \%$ respectively - indicating efforts are needed to sustain attention on metabolic risks.

To combat the poor physical health care of people with SMI, specialist nursing roles have been proposed. In a recent study, McKenna and colleagues [30] compared rates of metabolic monitoring between a mental health service where such a role was implemented, with a service where no such role existed. A specialist role led to a significant increase in the rate of metabolic monitoring, compared to services where this responsibility fell to case managers. Despite this specialist role initiating metabolic monitoring in $78 \%$ of first episode consumers, there were metabolic monitoring data missing in more than $42 \%$ of cases, with smoking the only parameter monitored in all cases. In reviewing the reasons for missing data, McKenna and colleagues note that specialist nursing staff 
identified several reasons for the missing data, including consumer anxiety towards needles (limiting the potential to undertake blood profiling), the complexity of procedures for collecting fasting blood glucose, logistical barriers to attending community-based pathology services (e.g., timing of appointments or transportation issues), and poor communication of diagnostic results between the mental health service and local medical officers.

Collectively, these studies highlight the poor use of metabolic monitoring in metropolitan mental health services. Such findings may well generalise to regional services. This paper reports on metabolic monitoring in a regionally located public mental health service within a large state of Australia. In mid-2013, the health service implemented a policy of routine metabolic monitoring of all consumers using antipsychotic medications or mood stabilisers. A standardised metabolic monitoring form was developed to be completed and uploaded to the electronic medical records database of consumers accessing the service. Given the high prevalence of cardiometabolic risk factors, and the repeated calls for routine metabolic monitoring in this population [31], the introduction of a standardised metabolic monitoring form represents a significant step in addressing the poor physical health of people with mental illness. However, the effectiveness of such a strategy remains to be evaluated, particularly in regional areas. Therefore the aims of the present study were to evaluate the frequency of use of the routine metabolic monitoring form and to examine the degree to which the forms were completed. Such data are important in evaluating the implementation of routine metabolic monitoring strategies, and the outcomes have important implications for mental health service delivery.

\section{Methods}

\section{Setting}

This study was undertaken in a mental health service in a city of approximately 75,000 people, located in regional Queensland, Australia. The service provides both inpatient and community mental health services and receives approximately 85 referrals per month.

\section{Design}

A retrospective file audit was undertaken examining the use of the metabolic monitoring form in the regional mental health service. Where multiple recording of metabolic monitoring data were contained on a single form for a consumer, the earliest data was taken as baseline data, with subsequent entries taken as the follow up time points.

\section{Data}

The files of 721 consumers were reviewed. The consumers' ages ranged from 13 to 83 years $(M=41.4$ years, $S D=14.6)$, over half were male $(58.4 \%)$, and the most common psychiatric diagnosis was schizophrenia (42.3\%) (see Table 1).

\section{Metabolic monitoring form}

As there is no consensus or minimum data set recommendation for metabolic monitoring forms, the form developed and implemented in this service was based on the needs of the service in consultation with clinicians. This form enables the recording of metabolic-related data, including anthropometrics (e.g., waist circumference, weight), blood markers of cardiovascular and endocrine health (e.g. triglycerides, alanine aminotransferase [ALT]), medication specific blood markers (e.g., valproate level, thyroid function test results, lithium

Table 1 Demographic and psychiatric diagnostic differences between consumers for whom the metabolic monitoring form had and had not been used

\begin{tabular}{|c|c|c|c|c|c|}
\hline & Total sample $(n=721)$ & Form used $(n=261)$ & Form not used $(n=460)$ & Effect size & $p$ value \\
\hline Age, mean (SD) years & $41.4(14.6)$ & $41.4(14.3)$ & $41.5(14.8)$ & $d=0.01$ & .902 \\
\hline Sex & & & & $\varphi=.12$ & .001 \\
\hline Males, $n(\%)$ & $421(58.4)$ & $175(41.6)$ & $246(58.4)$ & & \\
\hline Females, $n(\%)$ & $300(41.6)$ & $89(29.7)$ & $211(70.3)$ & & \\
\hline Diagnosis (ICD-10) ${ }^{a}$ & & & & Cramer's V $=.27$ & $<.001$ \\
\hline Schizophrenia (F20), n (\%) & $305(42.3)$ & $159(60.7)$ & $146(33.1)$ & & \\
\hline Bipolar disorder (F31), n (\%) & $84(11.7)$ & $23(27.4)$ & $61(72.6)$ & & \\
\hline Depressive disorders (F32, F33), n (\%) & $81(11.2)$ & $17(21.0)$ & $64(79.0)$ & & \\
\hline Anxiety disorders (F41), $n$ (\%) & $40(5.5)$ & $7(17.5)$ & $33(82.5)$ & & \\
\hline Other, $n(\%)$ & $193(26.8)$ & $56(29.0)$ & $137(71.0)$ & & \\
\hline
\end{tabular}

${ }^{\mathrm{a}}$ Diagnosis data were missing for $18(2.5 \%)$ consumers

SD standard deviation; ICD- 10 
levels), and electrocardiogram findings (e.g., rate, rhythm, abnormality). Data recorded on the form are uploaded to consumers' electronic health records.

\section{Procedures}

The data collection occurred between November 2014 and April 2015 and included all consumer electronic health records at the service. A trained research assistant extracted all data from consumers' metabolic monitoring forms to a spreadsheet. All data were de-identified and only data that appeared on the metabolic monitoring form was extracted.

\section{Statistical analysis}

To determine whether there were differences in the ages, sexes, and psychiatric diagnoses of consumers for whom the metabolic monitoring form had, and had not been used, appropriate inferential statistics (i.e., a paired $t$ test for age and $\chi^{2}$ tests for sex and psychiatric diagnoses) were applied. Consistent with sound statistical practices $[32,33]$, effect sizes were calculated and the issue of experiment-wise alpha inflation due to multiple tests was addressed. Effect sizes are reported in the form of Cohen's $d, \phi$, and Cramer's $V$. According to Cohen's [34] conventions, small, medium, and large effects are 0.2 , 0.5 , and 0.8 , respectively, for Cohen's $d$ and .10, .30, and .50 , respectively, for both $\phi$ and Cramer's $V$. With only three tests performed, setting alpha at .01 adequately addresses the problem of inflated experiment-wise error due to multiple testing. To assess the extent to which the form was being completed, descriptive statistics $(n, \%)$ are reported.
Ethics

Ethical clearance for the conduct of this retrospective file audit was granted by the health service (Queensland Health) and institutional (CQUniversity) human research ethics committees prior to the commencement of this study. Health service approval was granted to access data contained in consumer files.

\section{Results}

Metabolic monitoring forms were available for 261 (36\%) consumers. Comparing consumers where forms were available, with those were the form was not available, there were no differences in ages, but forms were present for higher percentages of males, and for consumers with schizophrenia (see Table 1). For the 261 consumers for whom baseline data were available, 59 $(22.6 \%)$ had follow up data recorded in their forms at three months, $87(33.3 \%)$ at six months, $42(16.1 \%)$ at 12 months, $18(6.9 \%)$ at 18 months, $9(3.4 \%)$ at 24 months, and $1(0.4 \%)$ at 36 months.

Data were not recorded for many of the measures included in the form. Although height, weight, and blood pressure were each recorded for over $80 \%$ of consumers, other data applicable to all consumers were recorded in half to two-thirds of forms (see Table 2). With respect to medication-specific measures, data were recorded in between $1.1 \%$ and $20.7 \%$ of forms. Data relating to cardiac function were never recorded (see Table 3).

\section{Discussion}

In the present study, we examined the use of an electronic metabolic monitoring form in a mental health

Table 2 Data recorded in the metabolic monitoring form at baseline

\begin{tabular}{|c|c|c|c|}
\hline & Measure & Observation recorded $-n(\%)$ & Observation not recorded $-n(\%)$ \\
\hline \multirow[t]{4}{*}{ Anthropometry } & Height & $223(85.4)$ & $38(14.6)$ \\
\hline & Weight & $228(87.4)$ & $33(12.6)$ \\
\hline & Body mass index & $192(73.6)$ & $69(26.4)$ \\
\hline & Waist circumference & $142(54.4)$ & $119(45.6)$ \\
\hline Blood pressure & Blood pressure & $218(83.5)$ & $43(16.5)$ \\
\hline Fasting blood glucose & Fasting blood glucose & $157(60.2)$ & $104(39.8)$ \\
\hline \multirow[t]{4}{*}{ Lipids } & Cholesterol & $147(56.3)$ & $114(43.7)$ \\
\hline & Low density lipoprotein & $127(48.7)$ & $134(51.3)$ \\
\hline & High density lipoprotein & $153(51.7)$ & $126(48.3)$ \\
\hline & Triglycerides & $144(55.2)$ & $117(44.8)$ \\
\hline \multirow[t]{3}{*}{ Liver function } & Alanine aminotransferase & $173(66.3)$ & $88(33.7)$ \\
\hline & Aspartate aminotransferase & $171(65.5)$ & $90(34.5)$ \\
\hline & Gamma-glutamyl transpeptidase & $169(64.8)$ & $92(35.2)$ \\
\hline \multirow[t]{2}{*}{ Renal function } & Urea & $173(66.3)$ & $88(33.7)$ \\
\hline & Creatinine & $172(65.9)$ & 89 (34.1) \\
\hline
\end{tabular}


Table 3 Medication-specific observations recorded in the metabolic monitoring forms at baseline

\begin{tabular}{llcl}
\hline & Measure $^{\mathrm{a}}$ & Observation recorded $-n(\%)$ & Observation not recorded $-n(\%)$ \\
\hline Endocrine & Prolactin level $^{\mathrm{b}}$ & $27(10.3)$ & $234(89.7)$ \\
Sodium valproate & Full blood count & $8(3.1)$ & $253(96.9)$ \\
Carbamazepine & Falproate level & $26(10.0)$ & $235(90.0)$ \\
& Full blood count & $1(0.4)$ & $260(99.6)$ \\
Lithium & Carbamazepine level & $3(1.1)$ & $258(98.9)$ \\
& Thyroid function test & $54(20.7)$ & $207(79.3)$ \\
Clozapine & Lithium level & $3(1.1)$ & $258(98.9)$ \\
\hline
\end{tabular}

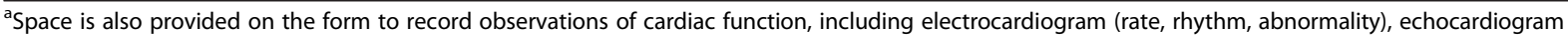
(if consumers are on Clozapine), and troponin. No forms contained observations for these measures

${ }^{\mathrm{b}}$ Instructions on form are to record if consumer is on Risperidone or Amisulpride

service in regional Queensland, Australia. Few studies have examined this aspect of mental health care, and those published to date have similar findings to ours. For example, Organ and colleges [27] audited 618 files from a large metropolitan mental health service and reported that there had been inconsistent recording of cholesterol (63\% of files), blood glucose (60\% of files), body weight (54\% of files) and blood pressure (44\% of files). Waist circumference data was present in only $7 \%$ of files. More recently, Rosenbaum and colleagues [28] reported that blood pressure was recorded on $92 \%$ of files and body mass index was recorded on $78 \%$ of files, whereas waist circumference was not reported on any of the 60 files audited at baseline. Finally, an audit of metabolic monitoring within a large metropolitan community mental health service revealed that files contained data on body weight (61 \% of files), blood glucose (59\% of files), lipids ( $49 \%$ of files), and blood pressure (38 \% of files) [35]. In contrast to the aforementioned studies, waist circumference was not included in the metabolic monitoring study described by Millar and colleagues, as this parameter was not assessed by the service. The findings, both from our study and from previous work, highlight both the lack of consensus on the parameters on metabolic monitoring and the extent of missing data on consumers' physical health. This missing data was especially evident in the recording of data relating to cardiac function, which, although detailed on the form, was not reported in any file audited.

For over a century, the health care inequalities mental health consumers routinely experience with respect to their physical health needs have been consistently documented ([36, 37], e.g., [38-41]). This inadequate attention to the physical health needs of mental health consumers is a likely contributor to the higher than expected mortality rates in this population [42]. Exposing the magnitude and consequences of this problem provides healthcare professionals and service providers with opportunities to gain a clearer understanding of the challenges inherent in the care of mental health consumers and to develop and trial possible solutions. Unfortunately, our research provides further evidence that the problem of poor physical healthcare of mental health consumers has not been adequately addressed.

Given the high prevalence of metabolic abnormalities, such as hypercholesterolaemia, among mental health consumers $[43,44]$, particularly those with schizophrenia [45], the findings of this study are particularly concerning. Our findings are, however, consistent with previous research showing that metabolic risk factors are not adequately monitored in mental health consumers [8]. Data had been entered into the electronic metabolic monitoring forms for one third of the consumers whose files were accessed. In these forms, substantial data were missing. This finding suggests that inadequate monitoring of metabolic risk factors reported in studies undertaken in mental health services in metropolitan area of Australia [28-30, 46] may be applicable to regionallylocated services. Consistent with other studies [27, 28] the absence of waist circumference data in many consumer files was also observed in this study.

Several factors may have contributed to the limited use of the form. Firstly, forms may not have been present in some electronic files because those consumers may not have had contact with the health service since the implementation of the routine metabolic monitoring form. Secondly, although service policy was that the electronic forms were to be used, a period of transitioning from paper-based to electronic forms means that some staff may have continued to use the paper-based forms. Discussions with the health service, however, indicated that some medication-specific observations (e.g., lithium levels) were not routinely conducted or only conducted in specific cases. Thus, it is unclear if the limited use of the form results from observations not being made or data being recorded in paper-based rather than electronic format. Thirdly, some staff may not have been trained in the use of the new initiative or may have 
chosen not to use the form based on personal preference. Finally, some consumers may have exercised their right to refuse to participate in some or all routine tests. This last point is important and highlights a limitation in the current form in that a consumer's refusal is not record and this may have contributed to the low reporting of some measures.

There are a number of service-level strategies that may advance the use of electronic metabolic monitoring forms to better manage the physical health care of people with SMI. For example, regular and ongoing audits to manage the transition from paper-based to electronic metabolic monitoring records could be initiated and linked to key performance indicators. These audits should identify additional information of interest, including the pharmacotheraputic outcomes and adverse events, and incorporate electronic flagging of results that are outside reference ranges, to ensure follow up and early intervention. Nurses, for example, with their holistic training, may be well-placed to facilitate a multidisciplinary approach to the mental and physical healthcare of mental health consumers [47]. Notably, a high number of nurses in mental health recognise physical health care as an important part of their role and express interest in ongoing education and training on cardiovascular health and diabetes [48]. Indeed, a number of studies have demonstrated the success of specialist nursing roles for coordinating the physical health care of mental health consumers $[23,26,30]$. Integration of these roles in to routine practice, however, is not widespread. As a result, the ongoing physical health care of mental health consumers in mental health settings remains disjointed.

The findings of the present study are not without limitation. The data for this study were obtained from the metabolic monitoring forms available in consumers' electronic health records only. Therefore, we have no knowledge of the medications consumers were taking at the time data were entered on the form. As such, we are unable to determine whether metabolic monitoring was more thorough or more frequent for those consumers who were taking medications known to increase cardiometabolic risks. Equally, we cannot determine if pharmacotherapeutic agents for the treatment of hypertension, hyperglycaemia, hypertriglycidaemia or hypoalphalipoprotienaemia were used. This limitation, however, highlights a significant issue with the current metabolic monitoring form. More broadly, the extent of missing data in the metabolic monitoring form suggests that either routine testing was not undertaken for some consumers or the data is reported elsewhere. Future studies in this field should consider the correlates to routine metabolic monitoring and the effect of clinician training on use of the form, to enhance its role in clinical decision-making.
The design of the study (a retrospective file audit) does not facilitate an understanding of the reasons why not all measures were present on the form. In mental health care services potential reasons for not undertaking or reporting data on metabolic risks include time constraints, views that screening can negatively affect rapport building, and absence of equipment [27, 46]. Qualitative research with nurses within mental health care indicate an awareness of the physical health problems experienced by people with SMI [49-51]. However, nurses express concerns regarding physical health care such as competing priorities, role delineation, and access to physical health interventions for consumers [49]. In an interview study that included nurses $(n=21)$, Ehrlich et al. [51] came to an overriding theme of "care boundaries" that nurses needed to navigate, as those boundaries shaped their individual agency to provide physical health care. The boundaries included "the illness (e.g. acuity), care provision processes (e.g. professional scope of practice), sectors (i.e. government, non-government, and private), the health-care system (e.g. funding constraints), and society (e.g. societal norms surrounding mental illness)" ([51], p. 245).

\section{Conclusions}

Inadequate physical health care of people with SMI is acknowledged as a widespread issue [52]. The present study demonstrates that a routine metabolic monitoring form placed in the consumers electronic health record was not utilised in a manner that maximises its potential benefit to the consumer or the health service. A great deal of missing data is evident and interventions or treatments to address metabolic abnormalities are not recorded on the form. Concerted, systematic changes are required within mental health services so that consumers can enjoy their right to equitable healthcare.

\section{Ethics}

Ethical clearance for the conduct of this retrospective file audit was granted by the Human Research Ethics Committees of Queensland Health (HREC/14/QPCH/ 150) and CQUniversity (H14/08-180) prior to the commencement of this study. Health service approval to access data contained in consumer files was granted under the Queensland Health Public Health Act.

\section{Consent to publish}

Not applicable.

\section{Availability of data and materials}

The Public Health Act approval to access the data used in the preparation of this manuscript does not extend to making it available in the public domain. Therefore, data and materials cannot be shared. 


\section{Abbreviations}

ALT: alanine aminotransferase; SMI: severe mental illness.

\section{Competing interests}

The authors declare that they have no competing interests.

\section{Authors' contributions}

$\mathrm{BH}$ contributed to the funding application, study design and manuscript revisions. CPP contributed to manuscript drafts and revisions. CJG contributed to data analysis, manuscript drafts and revisions. RS conceived the study, contributed to manuscript drafts and revisions. All authors approved the final draft and submission.

\section{Acknowledgements}

This research was supported by a grant from the Queensland Centre for Social Science Innovation.

\section{Author details}

'Synergy, Nursing and Midwifery Research Centre University of Canberra, Faculty of Health and ACT Health, Canberra, Australia. ${ }^{2}$ School of Medical and Applied Sciences, Central Queensland University, Bruce Highway, North Rockhampton, QLD 4702, Australia. ${ }^{3}$ Gaskin Research, Melbourne, Australia.

\section{Received: 7 July 2015 Accepted: 11 April 2016}

\section{Published online: 19 April 2016}

\section{References}

1. De Hert M, Correll CU, Bobes J, Cetkovich-Bakmas M, Cohen D, Asai I, et al. Physical illness in patients with severe mental disorders. I. Prevalence, impact of medications and disparities in health care. World psychiatry. 2011; 10:52-77

2. Jones D, Macias C, Barreira P, Fisher W, Hargreaves W, Harding C. Prevalence, severity, and co-occurrence of chronic physical health problems of persons with serious mental illness. Psychiatr Serv. 2004:55:1250-7.

3. Walker E, McGee RE, Druss BG. Mortality in mental disorders and global disease burden implications: A systematic review and meta-analysis. JAMA Psychiatry. 2015;72:334-41.

4. Scott D, Happell B. The high prevalence of poor physical health and unhealthy lifestyle behaviours in individuals with severe mental illness. Issues Ment Health Nurs. 2011;32(9):589-97. doi:10.3109/01612840.2011. 569846.

5. Vancampfort D, Vansteelandt K, Correll CU, Mitchell AJ, De Herdt A, Sienaert $P$, et al. Metabolic syndrome and metabolic abnormalities in bipolar disorder: A meta-analysis of prevalence rates and moderators. Am J Psychiatry. 2013;170(3):265-74. doi:10.1176/appi.ajp.2012.12050620.

6. American Diabetes Association, American Psychiatric Association, American Association of Clinical Endocrinologists. North American Association for the Study of Obesity. Consensus development conference on antipsychotic drugs and obesity and diabetes. Diabetes Care. 2004;27:596-601.

7. Buckley NA, Sanders P. Cardiovascular adverse effects of antipsychotic drugs. Drug Saf. 2000;23(3):215-28.

8. Mitchell AJ, Delaffon V, Vancampfort D, Correll CU, De Hert M. Guideline concordant monitoring of metabolic risk in people treated with antipsychotic medication: Systematic review and meta-analysis of screening practices. Psychol Med. 2012;42:125-47. doi:10.1017/S003329171100105X

9. Tek C, Kucukgoncu S, Guloksuz S, Woods SW, Srihari VH, Annamalai A. Antipsychotic-induced weight gain in first-episode psychosis patients: a meta-analysis of differential effects of antipsychotic medications. Early Interv Psychiatry. 2015. doi:10.1111/eip.12251.

10. Holt RI. The prevention of diabetes and cardiovascular disease in people with schizophrenia. Acta Psychiatr Scand. 2015. doi:10.1111/acps.12443.

11. Robson D, Gray R. Serious mental illness and physical health problems: a discussion paper. Int J Nurs Stud. 2007;44(3):457-66. doi:10.1016/j.jnurstu. 2006.07.013.

12. Lawrence D, Holman C, Jablensky A. Duty to care: Preventable physical illness in people with mental illness. Perth: University of Western Australia; 2001.

13. National Mental Health Commission. A contributing life: the 2012 national report card on mental health and suicide prevention. Sydney, Australia: National Mental Health Commission; 2012.
14. British Medical Association. Recognising the importance of physical health in mental health and intellectual disability: achieving parity of outcomes. London: British Medical Association; 2014.

15. Stanley SH, Laugharne JDE. Clinical guidelines for the physical care of mental health consumers: A comprehensive assessment and monitoring package for mental health and primary care clinicians. Aust N Z J Psychiatry. 2011;45(10):824-9. doi:10.3109/00048674.2011.614591.

16. Scott D, Platania-Phung C, Happell B. Quality of care for cardiovascular disease and diabetes amongst individuals with serious mental illness and those using antipsychotic medications. J Healthc Qual. 2012;34(5):15-21. doi:10.1111/j.1945-1474.2011.00155.x.

17. Littman AJ, Damschroder LJ, Verchinina L, Lai Z, Kim HM, Hoerster KD, et al. National evaluation of obesity screening and treatment among veterans with and without mental health disorders. Gen Hosp Psychiatry. 2015;37(1): 7-13. doi:10.1016/j.genhosppsych.2014.11.005.

18. Baller JB, McGinty EE, Azrin ST, Juliano-Bult D, Daumit GL. Screening for cardiovascular risk factors in adults with serious mental illness: A review of the evidence. BMC Psychiatry. 2015;15:55.

19. Cotes RO, de Nesnera A, Kelly M, Orsini K, Xie H, McHugo G, et al. Antipsychotic cardiometabolic side effect monitoring in a state community mental health system. Community Ment Health J. 2015. doi:10.1007/s10597-015-9833-0.

20. Saloojee S, Burns JK, Motala AA. Very low rates of screening for metabolic syndrome among patients with severe mental illness in Durban, South Africa. BMC Psychiatry. 2014;14:228. doi:10.1186/s12888-014-0228-5.

21. Shor R, Shalev A. Identifying barriers to improving the wellness of persons with severe mental illness in community residential mental health facilities. Soc Work Ment Health. 2013;11(4):334-48. doi:10.1080/15332985.2013.779360.

22. Lambert TJ, Newcomer JM. Are the cardiometabolic complications of schizoprehnia still neglected? Barriers to care. Med J Aust. 2009;190:S39-42.

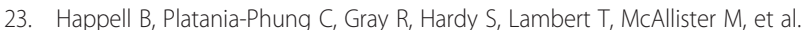
A role for mental health nursing in the physical health care of consumers with severe mental illness. J Psychiatr Ment Health Nurs. 2011;18(8):706-11. doi:10.1111/j.1365-2850.2010.01666.x.

24. Laursen TM, Nordentoft M, Mortensen PB. Excess early mortality in schizophrenia. Annu Rev Clin Psychol. 2014;10:425-48. doi:10.1146/annurevclinpsy-032813-153657.

25. Gladigau EL, Fazio TN, Hannam JP, Dawson LM, Jones SG. Increased cardiovascular risk in patients with severe mental illness. Intern Med J. 2013; 44:61-9. doi:10.1111/imj.12319.

26. Brunero S, Lamont S. Systematic screening for metabolic syndrome in consumers with severe mental illness. Int J Ment Health Nurs. 2009;18(2): 144-50. doi:10.1111/j.1447-0349.2009.00595.x.

27. Organ B, Nicholson E, Castle D. Implementing a physical health strategy in a mental health service. Australas Psychiatry. 2010;18(5):456-9. doi:10.3109/ 10398562.2010.506217.

28. Rosenbaum S, Nijjar S, Watkins A, Garwood N, Sherrington C, Tiedemann A. Nurse-assessed metabolic monitoring: A file audit of risk factor prevalence and impact of an intervention to enhance measurement of waist circumference. Int J Ment Health Nurs. 2014. doi:10.1111/inm.12057.

29. Thompson A, Hetrick SE, Alvarez-Jimenez M, Parker AG, Willet M, Hughes F, et al. Targeted intervention to improve monitoring of antipsychotic-induced weight gain and metabolic disturbance in first episode psychosis. Aust N Z J Psychiatry. 2011:45(9):740-8. doi:10.3109/00048674.2011.595370.

30. McKenna B, Furness T, Wallace E, Happell B, Stanton R, Platania Phung C, et al. The effectiveness of specialist roles in mental health metabolic monitoring: a retrospective cross-sectional comparison study. BMC Psychiatry. 2014;14:234.

31. Galletly C, Foley D, Waterreus A, Watts G, Castle D, McGrath J, et al. Cardiometabolic risk factors in people with psychotic disorders: The second Australian national survey of psychosis. Aust N Z J Psychiatry. 2012;46(8): 753-61. doi:10.1177/0004867412453089.

32. Gaskin CJ, Happell B. Power of mental health nursing research: A statistical analysis of studies in the International Journal of Mental Health Nursing. Int J Ment Health Nurs. 2013;22:69-75. doi:10.1111/j.1447-0349.2012.00845.x.

33. Gaskin CJ, Happell B. Power, effects, confidence, and significance: An investigation of statistical practices in nursing research. Int J Nurs Stud. 2014;51:795-806. doi:10.1016/j.jinurstu.2013.09.014.

34. Cohen J. Statistical power analysis for the behavioral sciences. 2nd ed. Hillsdale: Erlbaum; 1988.

35. Millar F, Sands N, Elsom S. Factors influencing cardiometabolic monitoring practices in an adult community mental health service. Int J Ment Health Nurs. 2014;23(6):479-89. doi:10.1111/inm.12085. 
36. Koranyi EK. Morbidity and rate of undiagnosed physical illnesses in a psychiatric clinic population. Arch Gen Psychiatry. 1979;36:414-9. doi:10.1001/archpsyc.1979.01780040056006.

37. Roca RP, Breakey WR, Fischer PJ. Medical care of chronic psychiatric outpatients. Psychiatr Serv. 1987;38:741-5. doi:10.1176/ps.38.7.741.

38. Chen $\mathrm{Y}-\mathrm{H}$, Lin $\mathrm{H}-\mathrm{C}$, Lin H-C. Poor clinical outcomes among pneumonia patients with schizophrenia. Schizophr Bull. 2011;37:1088-94. doi:10.1093/ schbul/sbq019.

39. Mitchell AJ, Lord O, Malone D. Differences in the prescribing of medication for physical disorders in individuals with v. without mental illness: Metaanalysis. Br J Psychiatry. 2012;201:435-43. doi:10.1192/bjp.bp.111.094532.

40. Gardner ER, Hail RCW. Medical screening of psychiatric patients. Orthomolecular Psychiatry. 1980;9:207-15.

41. Mitchell SW. Address before the fiftieth annual meeting of the American Medico-Psychological Association, held in Philadelphia, May 16th, 1894. J Nerv Ment Dis. 1894;19:413-37.

42. Mitchell AJ, Lord O. Do deficits in cardiac care influence high mortality rates in schizophrenia? A systematic review and pooled analysis. J Psychopharmacol. 2010;24(11):69-80. doi:10.1177/1359786810382056.

43. Fiedorowicz JG, Palagummi NM, Forman-Hoffman VL, Miller DD, Haynes WG. Elevated prevalence of obesity, metabolic syndrome, and cardiovascular risk factors in bipolar disorder. Ann Clin Psychiatry. 2008;20: 131-7. doi:10.1080/10401230802177722

44. Hasnain M, Vieweg WVR, Fredrickson SK, Beatty-Brooks M, Fernandez A Pandurangi AK. Clinical monitoring and management of the metabolic syndrome in patients receiving atypical antipsychotic medications. Prim Care Diabetes. 2009;3:5-15. doi:10.1016/j.pcd.2008.10.005.

45. De Hert M, Schreurs V, Vancampfort D, van Winkel R. Metabolic syndrome in people with schizophrenia: A review. World psychiatry. 2009;8:15-22. doi:10. 1002/j.2051-5545.2009.tb00199.x.

46. Hetrick S, Alvarez-Jimenez M, Parker A, Hughes F, Willet M, Morley K, et al. Promoting physical health in youth mental health services: ensuring routine monitoring of weight and metabolic indices in a first episode psychosis clinic. Australas Psychiatry. 2010;18(5):451-5. doi:10.3109/ 10398561003731189

47. Vreeland B. Bridging the gap between mental and physical health: A multidisciplinary approach. J Clin Psychiatry. 2007:68(4):26-33.

48. Happell B, Platania-Phung C, Scott D. Physical health care for people with mental illness: training needs for nurses. Nurse Educ Today. 2013;33(4):396-401. doi:10.1016/j.nedt.2013.01.015.

49. Happell B, Scott D, Nankivell J, Platania-Phung C. Screening physical health? Yes! But...: nurses' views on physical health screening in mental health care. J Clin Nurs. 2013;22(15-16):2286-97. doi:10.1111/j.1365-2702.2012.04325.x.

50. Happell B, Scott D, Platania-Phung C, Nankivell J. Should we or shouldn't we? Mental health nurses' views on physical health care of mental health consumers. Int J Ment Health Nurs. 2012;21(3):202-10. doi:10.1111/j.14470349.2011.00799.x

51. Ehrlich C, Kendall E, Frey N, Kisely S, Crowe E, Crompton D. Improving the physical health of people with severe mental illness: boundaries of care provision. Int J Ment Health Nurs. 2014;23(3):243-51. doi:10.1111/inm.12050.

52. De Hert M, Cohen D, Bobes J, Cetkovich-Bakmas M, Leucht S, Ndetei DM, et al. Physical illness in patients with severe mental disorders. II. Barriers to care, monitoring and treatment guidelines, plus recommendations at the system and individual level. World psychiatry. 2011;10(2):138-51.

\section{Submit your next manuscript to BioMed Central and we will help you at every step:}

- We accept pre-submission inquiries

- Our selector tool helps you to find the most relevant journal

- We provide round the clock customer support

- Convenient online submission

- Thorough peer review

- Inclusion in PubMed and all major indexing services

- Maximum visibility for your research

Submit your manuscript at www.biomedcentral.com/submit

) Biomed Central 